\title{
Analysis of energy poverty and its implications for sustainable development in Nigeria
}

\author{
FIDELIS O. OGWUMIKE \\ Department of Economics, University of Ibadan, Nigeria. \\ Email:foogwumike@yahoo.com \\ UCHE M. OZUGHALU \\ Department of Economics, University of Nigeria, Nsukka, Nigeria. \\ Email:uchemord@yahoo.com
}

Submitted 12 May 2013; revised 6 August 2014, 15 April 2015; accepted 16 May 2015; first published online 19 August 2015

\begin{abstract}
This study estimates and analyzes the incidence and determinants of energy poverty in Nigeria based on a simple multidimensional energy poverty index that it constructed. It also highlights the implications of energy poverty for sustainable development in Nigeria. The headcount ratio and the logistic regression technique are used. The study utilizes the Nigeria Living Standard Survey data set of 2004, obtained from the National Bureau of Statistics. The estimates show that energy poverty is pervasive in the country; it afflicts over 75 per cent of the population. The determinants of energy poverty in Nigeria include household size; educational level, gender and age of household head; general poverty; region of residence; and proportion of working members in the household. Efforts should be made to adequately tackle the problem of energy poverty in Nigeria. This is a major way to put the country on the path to rapid and sustainable development.
\end{abstract}

\section{Introduction}

A major dimension of poverty that has emerged in recent times and featured prominently in recent development and energy literatures is energy poverty. As observed in Pachauri and Spreng (2004), both energy and poverty have featured heavily in many recent policy documents of reputable agencies such as the World Bank, United Nations Development Programme (UNDP), World Energy Council and the UK's Department for International Development. Indeed, energy and poverty are highly related. For instance, the adequate supply of energy for rapid industrialization will, all other things being equal, pave the way for tremendous economic growth and massive employment opportunities that would lead to significant reduction in poverty. However, when we talk of energy poverty, it is 
worth noting that this phenomenon can be both a cause and a consequence of some other dimensions of poverty.

Energy poverty currently afflicts many regions of the world. However, Africa is apparently most hit by the problem. As pointed out in Iwayemi (2010), although Africa is richly endowed with both renewable and nonrenewable energy sources that far exceed its demand requirements for the next century, unfortunately most African countries are plagued by energy poverty; this is a reflection of their low real incomes and general state of economic underdevelopment. This unacceptable paradox of energy poverty in the midst of plenty has generated interesting debates among African scholars and policy makers with a view to finding an effective and efficient solution to the problem.

In order to pave the way for sustainable development, there should be an adequate supply of and access to modern energy sources. Generally, modern energy sources are far more environmentally friendly than traditional sources. Unfortunately, only very few people have access to modern energy sources in Africa, while an overwhelming proportion of the continent's population still use traditional sources of energy (OECD/IEA, 2010; World Bank, 2012).

Nigeria, which is said to be the 'giant of Africa' is frequently confronted with the problem of lack of access to modern sources of energy for most of her citizens. For instance, in 2004 and 2010, more than two-thirds of the country's households used firewood for cooking (NBS, 2005, 2010). This in itself suggests that there is a tremendous presence of energy poverty in the country and such a presence has some implications for sustainable development. It is pertinent to state here that an adequate supply of and access to modern energy sources is central to addressing a large number of contemporary development challenges such as climate change, food security, health, education, poverty and inequality. The foregoing therefore raises the following crucial questions: what is the extent of energy poverty in Nigeria? What are the determinants of energy poverty in the country? What are the implications of energy poverty for sustainable development in the country? To optimally address the foregoing questions, there is a need to use a multidimensional energy poverty index (MEPI) that covers some major dimensions of energy needs. Such an index will enable an excellent estimate of the magnitude of the problem of energy poverty and it will pave the way for reliable analyses of issues surrounding the problem. Unfortunately, there is apparently no detailed/comprehensive study on energy poverty in Nigeria and its determinants that is based on a robust multidimensional poverty index and on a nationally representative data set.

This study estimates and analyzes the incidence and determinants of energy poverty in Nigeria based on a simple MEPI. The study also highlights the implications of energy poverty for sustainable development in the country. The rest of the paper is organized as follows. The next section highlights some conceptual issues associated with the theme of the research while section 3 presents some linkages between energy and development. Section 4 presents a review of some theoretical and methodological issues as well as some empirical literature, and section 5 contains 
the methodology of the research. Section 6 is devoted to the presentation of results whereas section 7 highlights some implications of energy poverty for sustainable development in Nigeria. Section 8 contains the conclusion.

\section{Conceptual issues}

\subsection{Energy consumption and energy poverty}

As observed in Ogwumike and Ozughalu (2012), energy consumption refers to the use of energy for various purposes such as cooking, heating, lighting and powering machines. Households and individuals make use of various sources of energy. These sources can broadly be categorized as traditional and modern sources. Traditional sources are primitive and unsophisticated sources of energy whereas modern sources are highly sophisticated. Traditional sources are based on very low technology. Traditional sources of energy include firewood, charcoal, crop residue, sawdust and animal waste (UNDP and WHO, 2009; World Bank, 2012; Sher et al., 2014). Modern sources of energy, on the other hand, are based on very high technology. Modern sources of energy include kerosene, gas and electricity (UNDP and WHO, 2009; Ogwumike and Ozughalu, 2012; World Bank, 2012; Sher et al., 2014). It is important to state here that an energy source may be defined as traditional or modern depending on the purpose for which it is utilized. For example, kerosene may be regarded as modern for cooking whereas it is traditional or primitive for lighting. As stated earlier, modern energy sources are in general more environmentally friendly than traditional energy sources. This is because, among other things, modern energy sources bring about lower environmental pollution than traditional energy sources.

Moving on to energy poverty, there are various conceptualizations of the phenomenon. Some of the conceptualizations treat energy poverty as synonymous with fuel poverty whereas others make a distinction between the two terms. Some experts conceptualize energy poverty as a lack of access to sustainable modern energy services and products (Robic et al., 2012; Sher et al., 2014). This conceptualization implies that those who have access to only traditional sources of energy for their energy needs can be classified as energy poor. Energy poverty is said to be caused by a complex combination of factors, including a lack of physical availability of certain energy types, lack of income, and high costs associated with using energy, among others (Pachauri and Spreng, 2011). Some other experts conceptualize energy poverty as the inability of a household or an individual to cover its/his / her basic energy costs to keep homes adequately warm, cook food and have light; this conceptualization treats energy poverty as synonymous with fuel poverty. Energy poverty is also said to occur if the energy expenditure of a household or an individual is above 10 per cent of disposable income; transport fuels are not included here (Robic et al., 2012).

There is apparently no universally accepted definition of energy poverty. However, popular conceptualizations of energy poverty are usually based on minimum physical levels of basic energy needs, minimum energy expenditure required, access to modern energy sources and maximum proportion of energy expenditure in relation to total disposable income or 
total expenditure (see Foster et al., 2000; Barnes et al., 2010; Pachauri and Spreng, 2011; Robic et al., 2012).

\subsection{Sustainable development}

Sustainable development is a concept that has been defined in various ways. However, what is obvious in virtually all the popular definitions is that it is development that caters for the welfare of future generations. As stated in Fergus and Rowney (2005), as a society our goals should be considering development that sustains values reflecting progress in our relationships with one another as human beings, our place in the natural environment and, consequently, developments in what it means to be human beings. The concept of sustainable development was made popular by World Commission on Environment and Development of the United Nations in its 1987 report which is also known as the Brundtland Report. In the report, sustainable development is conceptualized to imply meeting the needs of the present generation without compromising the ability of future generations to meet their own needs (UN, 1987). It refers to a pattern of development that makes it possible for future generations to live at least as well as the current generation (Todaro and Smith, 2011). Economists consider a development path as sustainable if and only if the stock of overall capital assets remains constant or rises over time (Todaro and Smith, 2011). The concept of sustainable development implies limits - not absolute limits but limitations imposed by the present state of technology and social organization on environmental resources and by the ability of the biosphere to absorb the effects of human activities (UN, 1987). The quality of the environment is a major consideration in the analysis of sustainable development. Thus, any form of development that leads to environmental degradation is not considered as sustainable development.

\section{Linkages between energy and development}

There are very important linkages between energy and development. As observed in OECD/IEA (2010), making energy supply secure and reducing energy's contribution to climate change are often referred to as the two overriding challenges faced by the energy sector on the road to a sustainable future. Thus, relatively environmentally friendly energy coming from modern energy sources will have far lower adverse effects on the environment and climate compared to the highly environmentally harmful energy that comes from traditional energy sources. The foregoing implies that environmentally friendly energy is positively associated with development whereas environmentally harmful energy is inversely related to development. Access to modern sources of energy is very important for the provision of clean water, efficient sanitation and healthcare and it provides great benefits to development through the provision of reliable and efficient lighting, heating, cooking, mechanical power, transport and telecommunication services (OECD/IEA, 2010). When there is adequate supply of and access to relatively environmentally friendly energy from modern energy sources, environmental sustainability and cleanliness will be adequately maintained or enhanced; this will have a positive impact 
on health status, productivity, output and overall human welfare. On the contrary, in a situation where there is an inadequate supply of environmentally friendly energy or people lack access to such energy and thus resort to the use of traditional energy sources like firewood, charcoal, animal waste, crop residue and sawdust (in traditional ways like through open stoves) which are environmentally harmful - there will be a high level of pollution and environmental degradation which will bring about poor health status, low productivity, low output and a significant decrease in overall human welfare.

It is important to state at this point that the World Summit on Sustainable Development (WSSD) recognized the explicit link between access to energy services and poverty reduction. Energy services such as lighting, heating, cooking, mechanical power, motive power, transport and telecommunications are essential for socio-economic development, since they yield social benefits and support income and employment generation (UN, 2005). Energy is indispensable to industrialization, and industrialization is a major requirement for economic development. To guarantee optimal production in a modern industrializing or industrialized world, there must be an adequate supply of and access to energy. And to pave the way for sustainable development, there should be sufficient supply of and access to relatively environmentally friendly energy from modern energy sources.

\section{Review of theoretical and methodological issues as well as empirical literature}

A good starting point for a theoretical discourse on energy issues is the theory of transition. The theory is predicated on the assertion that households gradually climb an energy ladder which begins with traditional biomass fuels (such as firewood and charcoal), moves through commercial fuels (such as kerosene and liquefied petroleum gas) and culminates with electricity (Martins, 2005). As a nation develops, its per capita real income, knowledge as well as utilization and appreciation of sophisticated technologies increase significantly; this will make such a nation shift from the consumption of traditional fuels to the consumption of modern fuels (Ogwumike and Ozughalu, 2012). The theory of transition implies that underdevelopment is highly associated with energy poverty whereas as level of development increases, energy poverty is expected to reduce. Adequate access to electricity, which is at the zenith of the energy ladder, is evidently highly correlated with development (Onyeji et al., 2012). Electricity is a highly environmentally friendly energy source. But unfortunately, less developed regions of the world like sub-Saharan Africa are plagued with grossly inadequate access to electricity (Onyeji et al., 2012).

Economic theory that describes energy demand is predicated on the assumption that households determine what type of energy to use on the basis of rational consideration. As noted in Ouedraogo (2006) and Ogwumike and Ozughalu (2012), based on the theory of household utility maximization and its associated dual problem of cost minimization, households are said to have preferences among several categories of energy sources 
and to make the choice that maximizes their perceived indirect utility subject to their given income/expenditure constraints. Households' choice for a given source of energy will depend on certain specific socio-economic characteristics of each household such as sex of household head, age of household head, educational level of household head, household size, area/region of residence, ownership status of housing unit and general poverty status of household (Ouedraogo, 2006; Ogwumike and Ozughalu, 2012). As further pointed out in Ogwumike and Ozughalu (2012), economic factors and social conditions are major determinants of the demand for various sources of energy.

In the analysis of energy poverty, it is crucial to establish an energy poverty line. This line is usually based on how much energy consumption is necessary to maintain a bare minimum livelihood for households (Barnes et al., 2010). This line separates the energy poor from the non-energy poor. Determining an appropriate measure of energy poverty is associated with the energy poverty line. As observed in Barnes et al. (2010), there are several approaches that can be used in establishing the levels of energy poverty and they may be classified either as based on measures of physical energy requirements or on energy expenditures. In some approaches adopted in measuring energy poverty, the concept is considered to be analogous to a consumption poverty estimation that is based on the food energy intake or calorie necessities method. However, instead of food energy requirements measured in calories, energy poverty estimates are based on some technical provisions of energy services. The foregoing is basically the method used in the earliest approaches that classified and estimated the minimum quantities of energy to have a reasonable quality of life. The method caters for both direct and indirect energy needs. Direct energy needs include provisions for cooking, lighting, heating/cooling, preservation of food and pumping of water, as well as allowances for recreation and social occasions. Indirect energy needs, on the other hand, refer to energy that is embodied in additional goods and services that households use. However, a singular method of estimating energy poverty based on physical energy requirements is that which examines the physical energy needs of daily cooking and lighting; this is usually based on survey data (Barnes et al., 2010).

Pachauri and Spreng (2004) used a method that is based on energy expenditure as a proportion of total expenditures. As observed in Barnes et al. (2010), the rationale for such an expenditure-based approach is that many expenditure surveys indicate that poor households in general spend a larger part of their total expenditure on energy and this would obviously bring adverse hardship if the expense levels are too high. As household expenditures rise, on average, less and less money is spent on energy as a percentage of total income. But poor households on average spend higher and higher shares of their incomes on energy. A cut-off point of 10 per cent of total expenditure is popular in the literature as a common level of expenditure for poor households. Thus, any household whose energy expenditure is more than 10 per cent of its total expenditure may be regarded as energy poor (see Pachauri and Spreng, 2004).

Similar to the foregoing, energy poverty can also be based on the types of energy used by households at or below the overall expenditure poverty 
line that is estimated for a country (see Foster et al., 2000). This measure is predicated on the assumption that expenditure-poor households (in terms of per capita expenditure) are also likely to be energy poor. Here the energy poverty line is related more to consumption expenditures than to physical energy requirements.

A popular approach to measuring energy poverty is based on access to modern energy sources. Lack of access or inadequate access to modern energy sources, which leads to heavy dependence on traditional energy sources, is associated with energy poverty (Pachauri and Spreng, 2011). As observed in World Bank (2012), great reliance on solid fuels such as firewood and charcoal for cooking and heating is an indication of energy poverty. It has been recognized that access to modern energy sources such as electricity is crucial in the achievement of various development objectives. For instance, access to modern energy sources is essential for increasing productivity in agriculture, many welfare-enhancing services and the potentials of micro-enterprises to generate employment opportunities that are likely to help in eradicating extreme poverty and hunger. Further examples include the following: access to modern energy sources can reduce women's domestic burden of collecting firewood and allow them to utilize educational and employment opportunities as well as other socio-economic opportunities that can empower them and promote gender equality; and the use of environmentally friendly sources of cooking, heating and lighting energy in efficient appliances will minimize environmental pollution and contribute to reducing child mortality and guarantee environmental sustainability. Indeed, without adequate access to modern energy sources the likelihood of escaping poverty is very low.

A highly sophisticated and desirable method of estimating energy poverty is that based on the MEPI. This method caters for the multidimensional nature of energy poverty. It is well known that single indicators are straightforward to handle and they provide powerful and unbiased messages that are easy to interpret with regard to one specific dimension; however, such indicators are often unsuitable for certain issues like sustainable development (Nussbaumer et al., 2011, 2012). But the MEPI captures a set of energy deprivations that may affect a household or an individual. It is more comprehensive than single indicators and it evidently performs better in accessing the incidence of energy poverty. And, as pointed out in Nussbaumer et al. $(2011,2012)$, the MEPI provides a new apparatus to support policy making.

The use of the headcount measure is very popular in measuring the incidence of multidimensional poverty (Sher et al., 2014). This is simply the proportion of those that are in multidimensional poverty in relation to the total population.

Let us now examine some relevant empirical literature. As observed in Ogwumike and Ozughalu (2012), many empirical studies relating to energy consumption, poverty and the environment have been carried out. These studies involved trend analysis utilizing descriptive statistics and ratio analysis, and determinants of energy consumption (see Aina and Odebiyi, 1998; Pachauri and Spreng, 2004; Martins, 2005; Ouedraogo, 2006). However, empirical works on energy poverty are relatively very scanty; 
they include Foster et al. (2000); Pachauri and Spreng (2004); Barnes et al. (2010), Nussbaumer et al. (2011, 2012), and Sher et al. (2014).

Foster et al. (2000) estimated energy poverty using data from Guatemala, based on the conceptualization that a household is energy or fuel poor if its energy consumption does not meet basic energy needs. The study utilized the Foster-Greer- Thorbecke (FGT) index to analyze energy poverty in Guatemala. The fuel/energy poverty line used in the study was derived by computing the average energy consumption of households whose overall per capita consumption level fell within plus or minus 10 per cent of the US\$1 (purchasing power parity adjusted) income poverty line used in the international literature on income/expenditure poverty. This gave a subsistence energy threshold of 2,125 kilowatt-hours per year. The study found, among other things, that one-fourth of the population with access to electricity was fuel poor whereas half of the population without access to electricity was fuel poor. Pachauri and Spreng (2004), among other things, utilized an engineering estimate that determined the direct energy required to satisfy the basic needs of Indian households. The study showed, among other things, that the majority of households in India used a combination of biomass and kerosene to meet their direct energy needs; when comparing annualized cost, firewood remained the attractive option for households.

Barnes et al. (2010), among other things, estimated the incidence of energy poverty in rural Bangladesh, using an energy poverty line that was based on estimates of household minimum energy requirements; the study utilized a cross-sectional data set based on a 2004 survey of 2,300 households in rural Bangladesh. The study found, among other things, that some 58 per cent of rural households in Bangladesh were energy poor compared to 45 per cent that were income poor.

Nussbaumer et al. (2011, 2012) estimated energy poverty incidence and intensity for various African countries, including Nigeria, based on a MEPI that catered for the following dimensions: cooking, lighting, services provided by means of household appliances, entertainment/education and communication. The study utilized the Alkire-Foster (AF) methodology. The study found, among other things, that the degree of energy poverty among the various African countries considered ranged from acute energy poverty (i.e., MEPI $>0.9$, for example, Ethiopia) to moderate energy poverty (i.e., MEPI < 0.6; examples include Angola, Egypt, Morocco, Namibia and Senegal). The energy poverty incidence and intensity of energy poverty for Nigeria were estimated as 81 per cent and 0.75 respectively.

Sher et al. (2014) employed the AF methodology to measure multidimensional energy poverty at a provincial level in Pakistan. The study used the headcount measure. The study found, among other things, that multidimensional energy poverty incidence ranged from 47 to 69 per cent across the four provinces of Pakistan used in the study, and indoor pollution was found to be the largest contributor to multidimensional energy poverty incidence in all the four provinces while cooking fuel was the second largest contributor. The study used similar dimensions/indicators to those used in Nussbaumer et al. $(2011,2012)$. It is pertinent to point out that Nussbaumer et al. $(2011,2012)$ and Sher et al. (2014) applied a MEPI that was too 
comprehensive and this could overstate the magnitude of the problem in a less developed country like Nigeria. In Nigeria, the basic energy needs are cooking, heating and lighting. The average households in the country evidently use energy to satisfy only these needs. Thus, it is better to focus on only the dimensions that are associated with basic energy needs in Nigeria when analyzing energy poverty for the country. Also, none of the studies reviewed analyzed the determinants of energy poverty and the implications of energy poverty for sustainable development. The foregoing gaps form part of the motivation for this study. This study will analyze energy poverty based on a MEPI that is predicated on only the dimensions that are associated with the basic energy needs in Nigeria; the study will also analyze the determinants of energy poverty and its implications for sustainable development in the country.

It is pertinent to point out here that, in analyzing the determinants of energy use/consumption or energy poverty, the logit regression technique is apparently very popular. The logit procedure is a maximum likelihood estimator of parameters given the non-linear probability distribution of the random error. The logit model gives parameter estimates that are asymptotically efficient, consistent and normal and the analogue of the regression $t$-test can be applied; it produces statistically sound results (Gujarati and Porter, 2009; Ozughalu, 2010).

\section{Methodology}

This study utilizes the 2004 Nigeria Living Standard Survey (NLSS) data set, obtained from the National Bureau of Statistics (NBS), Abuja, Nigeria. The NBS is the apex statistical agency in Nigeria. The 2004 NLSS data set is nationally representative in nature and it contains all the information needed for this study. The data set is currently one of the most comprehensive and complete data sets in Nigeria and it is readily available.

Tables 1, 2 and 3 are derived from the data set. Table 1 shows the percentage distribution of Nigerian households by main source of energy used for cooking and main source of energy used for lighting. Table 2 shows mean per capita household expenditures by quintiles; table 3 shows ownership of cooking stove and gas cooker by quintiles. Table 1 shows that most households in Nigeria use firewood for cooking (69.98 per cent) while most households in the country use kerosene and mains electricity for lighting; 49.66 per cent use kerosene while 45.39 per cent use mains electricity. Table 2 shows that mean per capita household expenditures (food, non-food and total) vary with quintiles. Table 3 shows that both ownership of cooking stove and ownership of gas cooker vary directly with income/expenditure quintiles. However, the extent of ownership for the highest quintile is far more for gas cooker than for cooking stove.

Drawing on Alkire and Foster $(2007,2011)$ and Nussbaumer et al. (2011, 2012), we construct a simple MEPI based on three major dimensions of energy deprivation. The dimensions are cooking, indoor pollution and lighting. The indicators associated with these dimensions are access to modern energy source for cooking, causing indoor pollution and access to mains electricity and/or electricity from generator. These indicators as 
Table 1. Percentage distribution of Nigerian households by main source of energy used for cooking and main source of energy used for lighting

\begin{tabular}{|c|c|c|c|}
\hline \multicolumn{2}{|c|}{ Main source of energy for cooking } & \multicolumn{2}{|c|}{ Main source of energy for lighting } \\
\hline Energy source & $\begin{array}{l}\text { Proportion of total } \\
\text { number of households } \\
\text { using the energy } \\
\text { source }(\%)\end{array}$ & Energy source & $\begin{array}{l}\text { Proportion of total } \\
\text { number of households } \\
\text { using the energy } \\
\text { source }(\%)\end{array}$ \\
\hline Firewood & 69.98 & Kerosene & 49.66 \\
\hline Charcoal & 0.84 & Gas & 0.98 \\
\hline Kerosene/oil & 26.55 & Mains electricity & 45.39 \\
\hline Gas & 1.11 & $\begin{array}{l}\text { Electricity from } \\
\text { generator }\end{array}$ & 0.45 \\
\hline Electricity & 0.52 & Battery & 0.04 \\
\hline $\begin{array}{l}\text { Crop residue } \\
\text { or sawdust }\end{array}$ & 0.09 & Candle & 0.1 \\
\hline Animal waste & 0.07 & Firewood & 2.41 \\
\hline Others & 0.84 & Others & 0.97 \\
\hline Total & 100 & Total & 100 \\
\hline
\end{tabular}

Source: 2004 NLSS data set.

Table 2. Mean per capita household expenditures by quintiles

\begin{tabular}{lccc}
\hline Quintile & $\begin{array}{c}\text { Per capita food } \\
\text { expenditure }(\sharp)\end{array}$ & $\begin{array}{c}\text { Per capita non-food } \\
\text { expenditure }(\sharp)\end{array}$ & $\begin{array}{c}\text { Per capita total } \\
\text { expenditure }(\sharp)\end{array}$ \\
\hline 1 & 3,706 & 3,520 & 7,226 \\
2 & 7,796 & 5,467 & 13,263 \\
3 & 11,663 & 7,572 & 19,235 \\
4 & 16,381 & 11,880 & 28,261 \\
5 & 29,408 & 39,543 & 68,951 \\
Total & 17,094 & 18,506 & 35,600 \\
\hline
\end{tabular}

Source: National Bureau of Statistics (2005).

Table 3. Ownership of cooking stove and gas cooker by quintiles

\begin{tabular}{lcc}
\hline $\begin{array}{c}\text { Ownership of cooking stove: } \\
\text { proportion of the total } \\
\text { number of the asset }(\%)\end{array}$ & $\begin{array}{c}\text { Ownership of gas cooker: } \\
\text { proportion of the total } \\
\text { number of the asset }(\%)\end{array}$ \\
\hline 1 & 2.16 & 0.54 \\
2 & 7.4 & 1.23 \\
3 & 12.88 & 1.77 \\
4 & 24.66 & 15 \\
5 & 52.9 & 81.46 \\
Total & 100 & 100.00 \\
\hline
\end{tabular}

Source: National Bureau of Statistics (2005). 
Table 4. Construction of multidimensional energy poverty index

\begin{tabular}{|c|c|c|c|c|}
\hline Dimension & Indicator & Weight & Variable & $\begin{array}{c}\text { Deprivation cut-off } \\
\text { (poor if ...) }\end{array}$ \\
\hline Cooking & $\begin{array}{l}\text { Access to modern } \\
\text { energy source } \\
\text { for cooking }\end{array}$ & 0.4 & $\begin{array}{l}\text { Type of energy } \\
\text { source for } \\
\text { cooking }\end{array}$ & $\begin{array}{l}\text { Household uses } \\
\text { any energy } \\
\text { source besides } \\
\text { kerosene/oil, } \\
\text { gas and } \\
\text { electricity for } \\
\text { cooking }\end{array}$ \\
\hline $\begin{array}{l}\text { Indoor } \\
\text { pollution }\end{array}$ & $\begin{array}{l}\text { Causing indoor } \\
\text { pollution }\end{array}$ & 0.3 & $\begin{array}{l}\text { Cooking or } \\
\text { heating on } \\
\text { stove or open } \\
\text { fire (no hood/ } \\
\text { chimney); } \\
\text { if using } \\
\text { any energy } \\
\text { source besides } \\
\text { electricity } \\
\text { and/or gas } \\
\text { in cooking or } \\
\text { heating indoors }\end{array}$ & True \\
\hline Lighting & $\begin{array}{l}\text { Access to mains } \\
\text { electricity } \\
\text { and/or } \\
\text { electricity from } \\
\text { generator }\end{array}$ & 0.3 & $\begin{array}{l}\text { Has access } \\
\text { to mains } \\
\text { electricity } \\
\text { and/or } \\
\text { electricity from } \\
\text { generator }\end{array}$ & False \\
\hline
\end{tabular}

Source: Computed by the authors

well as the associated weights, variables and deprivation cut-off are shown in table 4 . The choice of indicators is skewed in favour of cooking energy because cooking is the most basic energy need in Nigeria. Thus, cooking indicator is given higher weight than the other indicators while lighting and indoor pollution indicators are assumed to have the same weight. As indicated in Nussbaumer et al. (2012), the issue of how to optimally assign weights can be challenging and is an arbitrary and value-driven process.

As can be seen from table 4, the dimensions covered are cooking, indoor pollution and lighting. These are basic dimensions that easily capture deprivation in the use of highly environmentally friendly energy sources. Let $n$ represent the total number of households in the population and let $d$ represent the number of dimensions under consideration. $Y=\left[y_{i j}\right]$ represents the $n \times d$ matrix of achievements for $i$ households across $j$ variables. The typical entry $y_{i j}>0$ is the achievement of household $i=1,2, \ldots, n$ in variable $j$. Each row vector $y_{i}=\left(y_{i 1}, y_{i 2}, \ldots, y_{i d}\right)$ represents household $i$ 's achievements in the various dimensions, while each column vector $y_{j}=\left(y_{1 j}, y_{2 j}, \ldots, y_{n j}\right)$ gives the distribution of achievements in the 
variable $j$ across households. The weighting of indicators can either be done evenly or unevenly. A weighting vector $w$ is composed of the elements $w_{j}$ corresponding to the weight that is applied to the variable $j$. We define $\sum_{j=1}^{d} w_{j}=1$. We further define $z_{j}$ as the deprivation cut-off in variable $j$, and then identify all households deprived in all the chosen variables. Let $h=\left[h_{i j}\right]$ be the deprivation matrix whose typical element $h_{i j}$ is defined by $h_{i j}=w_{j}$ when $y_{i j}<z_{j}$ and $h_{i j}=0$ when $y_{i j} \geq z_{j}$. The entry $i j$ of the matrix is equivalent to the variable weight $w_{j}$ when a household $i$ is deprived in variable $j$, and 0 when the household is not deprived. In conjunction with the foregoing, we construct a column vector $m$ of deprivation counts, where the $i^{t h}$ entry $m_{i}=\sum_{j=1}^{d} h_{i j}$ represents the sum of the weighted deprivations suffered by a household $i$. We then identify the households that are in multidimensional energy poverty by defining a cut-off $k>0$ and applying it across the column vector, and consider a household as multidimensional energy poor if its weighted deprivation count $m_{i}$ exceeds or is equal to $k$. For each household, the sum of the weighted deprivation cut-off is defined as the household's MEPI. We select 0.6 as our multidimensional energy poverty line. Thus, any household whose MEPI is greater than or equal to 0.6 is regarded as energy poor. This implies that any household that is deprived in at least two out of the selected three indicators that are associated with the identified basic energy needs in Nigeria is regarded as being in energy poverty. Given that we are utilizing the multidimensional approach to energy poverty measurement and analysis, it is desirable that for a household to be considered as energy poor it must be deprived in at least two basic indicators and not in only one basic indicator. It is worthwhile to state here that indoor pollution is included as a separate indicator because it directly causes air pollution that brings about health problems that plague households; it directly affects the quality of the environment adversely. Energy poverty is multidimensional in nature; thus, it is crucial to use a multidimensional approach in its analysis. And the multidimensional approach utilized in this study is considered to be highly robust.

Our measure of energy poverty is the headcount ratio. This is given as $H=\frac{q}{n}$ where $H$ is energy poverty headcount or energy poverty incidence, $q$ is the number of households that are in energy poverty and $n$ is the total number of households in the population. The headcount ratio is the simplest and most common poverty measure. The measure is very useful in tracking changes in the percentage of the population living in poverty.

To estimate the determinants of energy poverty we employ the following logit model:

$$
\begin{aligned}
L_{i}= & \ln \left(\frac{P_{i}}{1-P_{i}}\right)=\alpha_{0}+\alpha_{1} H S+\alpha_{2} \text { AHH }+\alpha_{3} \text { SHH }+\alpha_{4} \text { ELHH }+\alpha_{5} \text { North } \\
& +\alpha_{6} \text { Urban }+\alpha_{7} \text { RFETE }+\alpha_{8} \text { POVERTY }+\alpha_{9} \text { PWM }+\alpha_{10} \ln p c \exp d r \\
& +\alpha_{11} \text { PCM }+\alpha_{12} \text { POM }+\varepsilon_{i}
\end{aligned}
$$

where $L_{i}$ is the logit (i.e., the natural logarithm of the odds ratio); $P_{i}=1$ if household is energy poor and $P_{i}=0$ if household is not energy poor; 
$\left(\frac{P i}{1-P i}\right)$ is simply the odds ratio in favour of being in energy poverty; $H S$ is household size; $A H H$ is age of household head (in years); $S H H$ is sex of household head (male $=1$, female $=0$ ); $E L H H$ is educational level of household head (in terms of years of formal schooling); North is living in Northern Nigeria (yes $=1$, no $=0$ ); Urban is living in urban area (yes $=1$, no $=0$ ); RFETE is ratio of food expenditure to total expenditure (in percentage); POVERTY is household general poverty status (yes $=1$, no $=0$ ); general poverty is defined here as when a household's per capita expenditure is less than two-thirds of mean per capita household expenditure in regionally deflated prices; $P W M$ is proportion of working members in the household; ln $p c \exp d r$ is natural logarithm of per capita expenditure in regionally deflated prices (this is a proxy for income); PCM is proportion of household members that are between 0 and 15 years; POM is proportion of household members that are more than 60 years old; and $\varepsilon_{i}$ is the stochastic error term.

The a priori expectations are $\alpha_{0}, \alpha_{1}, \alpha_{5}, \alpha_{7}, \alpha_{8}, \alpha_{11}, \alpha_{12}>0 ; \alpha_{2}, \alpha_{3}, \alpha_{4}, \alpha_{6}$, $\alpha_{9}, \alpha_{10}<0$.

\section{Presentation of results}

Table 5 shows the extent of lack of access to modern energy sources for cooking, generation of indoor pollution and lack of access to main electricity and/or electricity from generator. The table indicates that almost 72 per cent of Nigerian households lack access to modern energy sources for cooking, over 98 per cent generate indoor pollution and over 54 per cent lack access to mains electricity and/or electricity from generator.

Table 6 shows national energy poverty level, zonal energy poverty level and energy poverty incidence by urban and rural areas. As can be seen from the table, 75.5 per cent of Nigerians are energy poor. This indicates that the magnitude of the problem is very high in the country. The North East zone has the highest energy poverty level followed by the North West zone and the North Central zone, respectively. The South West zone has the least incidence of energy poverty followed by the South East zone and the South South zone, respectively. Thus, energy poverty is apparently more pronounced in Northern Nigeria than in Southern Nigeria. The table further shows that energy poverty is far higher in the rural area than in the urban area.

Table 7 shows estimates of determinants of energy poverty in Nigeria. As can be seen from the table, the model is generally robust. All the regressors, on aggregate, have significant impact on energy poverty; this is shown by the fact that the likelihood ratio statistic is statistically significant at 1 per cent. Two pseudo $R^{2}$ are presented, namely the Cox \& Snell $R^{2}$ and the Nagelkerke $R^{2}$; these are measures of goodness of fit and are 0.295 and 0.495, respectively. However, as noted in Gujarati and Porter (2009), in binary regressand models, goodness of fit is of secondary importance. What matters are the signs of the regression coefficients and their statistical significance. 
Table 5. Extent of lack of access to modern energy sources for cooking, generation of indoor pollution and lack of access to mains electricity and/or electricity from generator

Access to modern energy sources for cooking

Percentage of Nigerian households that lack access to modern energy sources for cooking

Percentage of Nigerian households that have access to modern energy sources for cooking

Generation of indoor pollution

Percentage of Nigerian households that generate indoor pollution

Percentage of Nigerian households that do not generate indoor pollution

Access to mains electricity and/or electricity from generator

Percentage of Nigerian households that lack access to mains electricity and/or electricity from generator

Percentage of Nigerian households that have access to mains electricity and/or electricity from generator

Source: Computed by the authors from the 2004 NLSS data set.

Table 6. Energy poverty in Nigeria: national, by zone and by sector

\begin{tabular}{lc}
\hline Category & $\begin{array}{c}\text { Energy poverty } \\
\text { incidence }(\%)\end{array}$ \\
\hline National & 75.5 \\
Zone & \\
South South & 76.2 \\
South East & 75.3 \\
South West & 35.8 \\
North central & 82.3 \\
North East & 96.5 \\
North West & 90.7 \\
Urban and rural areas & \\
Urban area & 50.9 \\
Rural area & 94.9 \\
\hline
\end{tabular}

Source: Computed by the authors.

Most of the parameter estimates are statistically significant at 1 per cent. Virtually all the parameter estimates have the expected a priori signs. Sex of household head with respect to male headship, educational level of household head, residing in urban area and proportion of working members of household are negatively associated with energy poverty; they reduce the odds in favour of being in energy poverty. On the other hand, household size, age of household head, living in Northern Nigeria, ratio of food expenditure to total expenditure and general poverty are positively related 
Table 7. Determinants of energy poverty in Nigeria

\begin{tabular}{|c|c|c|c|c|}
\hline Variable & $B$ & $S E$ & Sig & $\operatorname{Exp}(B)$ \\
\hline$H S$ & $0.072 *$ & 0.013 & 0.000 & 1.075 \\
\hline AHH & $0.007^{*}$ & 0.002 & 0.008 & 1.007 \\
\hline $\mathrm{SHH}$ & $-0.149^{* *}$ & 0.071 & 0.035 & 0.861 \\
\hline ELHH & $-0.079^{*}$ & 0.004 & 0.000 & 0.924 \\
\hline North & $0.927^{*}$ & 0.058 & 0.000 & 2.528 \\
\hline Urban & $-2.478^{*}$ & 0.052 & 0.000 & 0.084 \\
\hline RFETE & $0.020^{*}$ & 0.001 & 0.000 & 1.020 \\
\hline POVERTY & $0.228^{*}$ & 0.082 & 0.005 & 1.256 \\
\hline$P W M$ & $-0.601^{*}$ & 0.087 & 0.000 & 0.548 \\
\hline $\operatorname{Ln} p c \exp d r$ & -0.028 & 0.051 & 0.587 & 0.973 \\
\hline$P C M$ & 0.093 & 0.127 & 0.464 & 1.097 \\
\hline POM & 0.100 & 0.152 & 0.510 & 1.105 \\
\hline Constant & $1.782^{*}$ & 0.583 & 0.002 & 5.940 \\
\hline \multicolumn{5}{|c|}{$\begin{array}{l}\text { Cox \& Snell } R^{2}=0.295 ; \text { Nagelkerke } R^{2}=0.495 \text {; Likelihood ratio } \\
\quad \text { statistic }=6,709.945\end{array}$} \\
\hline
\end{tabular}

Notes: ${ }^{*}$ Significant at $1 \%$ level; ${ }^{* *}$ significant at $5 \%$ level.

$B$ represents the various parameter estimates; $S E$ stands for the standard errors associated with the various parameter estimates; Sig stands for the levels of significance or the probability values of the various parameter estimates; $\operatorname{Exp}(B)$ represents the odds ratios associated with the various parameter estimates (these are obtained by taking the natural anti-logarithms of the respective parameter estimates).

Source: Computed by the authors.

to energy poverty; they increase the odds in favour of being in energy poverty. The constant term is statistically significant at 1 per cent and is positively related to energy poverty. Household income represented by per capita household expenditure, proportion of children in the household and proportion of old people in the household do not significantly affect energy poverty in Nigeria even though they have the expected a priori signs.

\section{Implications of energy poverty for sustainable development in Nigeria}

Based on the MEPI used in this study, the high incidence of energy poverty implies that most people use very inferior sources of energy for their cooking, heating and lighting needs. It also implies that they do not use environmentally friendly cookers. To get inferior sources of energy like firewood requires overexploitation of the environment through massive deforestation and other activities that are harmful to the environment. These are inimical to sustainable development because they jeopardize the welfare of future generations. Environmental pollution comes as a result of the use of such sources of energy for cooking, heating and lighting; indeed, the use of such energy sources brings about air pollution which 
adversely affects health status. As a matter of fact, the indoor pollution that results from cooking on stove or open fire is a major source of health hazards which negatively affect quality of life. For example, the World Health Organisation (WHO) reported that a cook using firewood in the household can inhale an amount of benzopyrene equivalent to 20 packets of cigarettes a day (Aina and Odebiyi, 1998). The security of household livelihoods rests on the health of its members. Ill health as a result of exposure to indoor air pollution reduces earnings capacities, productivity, output and income. In addition, the individual incurs more expenses for healthcare and medication. The poor illumination that comes as a result of the use of unsophisticated sources of energy is a major cause of eye problems and other health problems. Such problems have an adverse impact on general quality of life and sustainable development. Moreover, when people lack basic energy services and resources, they are most unlikely to be very alert and productive in their workplaces; this will negatively affect the way they would provide for upcoming generations.

Deforestation due to the demand for firewood and other wood products depletes natural resources without due consideration for the welfare of future generations. For example, Sambo (2009) reported that about 350,000 ha of natural vegetation and forests are destroyed annually in Nigeria, and the deforestation rate is expected to increase alongside the increasing demand for traditional/environmentally harmful energy sources. A recent estimate shows that Nigeria consumes over 50 million metric tonnes of firewood annually; this rate exceeds the replenishment rate through various afforestation programmes (Sambo, 2009). As further noted in Sambo (2009), the heavy demand for firewood for domestic and commercial uses is a major cause of desertification in the northern part and erosion in the southern part of the country. Desertification and erosion are major forms of environmental degradation. Thus, the significant presence of desertification and erosion in Nigeria due to the tremendous use of inferior sources of energy is a great impediment to sustainable development in the country.

Given the health, environmental and poverty implications of the use of inferior and environmentally harmful energy sources for cooking, heating and lighting, one may be forced to ask as follows: what options are available for sustainable development? In the short run, individuals, families, communities and governments need to take actions to mitigate the effects of indoor air pollution. Firewood cooking stoves may be modified to minimize the amount of wood used and the pollution generated, while still ensuring that more heat is generated to cook faster. Moreover, such modified stoves that rely more on charcoal and sawdust which burn better than wood in terms of emitting $\mathrm{CO}_{2}$ can be produced with incentives to both the private sector and households to use them. Government policies and incentives should encourage the inclusion of a chimney in houses to minimize indoor air pollution due to the use of inferior/environmentally harmful energy sources like firewood in cooking and heating. Efforts should also be made by individuals, communities and governments to replant trees to ensure the sustainability of the ecosystem and forest.

In the long run, the government will need to extend the use of modern cooking fuels and electricity to a greater proportion of both the urban 
and rural population. As noted in IEA and OECD (2004), the goal of significantly reducing poverty could only be met if governments act decisively to accelerate the transition to modern energy sources and break the vicious cycle of poverty and human underdevelopment in the world's poorest countries. There is a lot of scope for actualizing this transition in the Nigerian case; as the power sector reform is carried out, the highly environmentally friendly energy supply will increase. Hence, government incentives to encourage the use of modern energy sources for cooking will pay off for the households and investors in the energy sector as well as investors in modern energy cooking facilities. The role of incentives to households to transit from firewood and other environmentally harmful sources of energy to modern energy sources cannot be overemphasized, given that the bulk of the users of such traditional energy sources are poor.

\section{Conclusion}

Given that the magnitude of energy poverty is very high in Nigeria, adequate steps should be taken to give the average Nigerian access to modern energy sources. In tackling energy poverty in the country, the zones/areas that have the highest incidences of energy poverty should be attended to before others. Adequate employment and education should be provided for Nigerians; this will have a significant positive impact on energy poverty. Efforts should be intensified to make households in Nigeria have small families and only produce children they can adequately cater for.

Nigeria aims to become one of the 20 most developed economies within a short time. To make this aim realisable, an effort should be made to adequately reduce or even obliterate energy poverty in the country. There is no way the nation can achieve greatness when energy poverty is prevalent in the country. The government should, therefore, create the necessary incentives to enable households that are energy poor to transit to modern energy sources, and exit from the vicious cycle of energy poverty.

\section{References}

Aina, O.I. and A.I. Odebiyi (1998), 'Domestic energy crisis in Nigeria: impact on women and family welfare', African Economic History 26: 1-14.

Alkire, S. and J. Foster (2007), 'Counting and multidimensional poverty measurement', Oxford Poverty \& Human Development Initiative (OPHI) Working Paper Series No. 7, University of Oxford, Oxford.

Alkire, S. and J. Foster (2011), 'Counting and multidimensional poverty measurement', Journal of Public Economics 95(7-8): 476-487.

Barnes, D., S.R. Khandker, and H.A. Samad (2010), 'Energy access, efficiency and poverty: how many households are energy poor in Bangladesh', World Bank Policy Research Working Paper No. 5332, World Bank, Washington, DC.

Fergus, A.H.T. and J.I.A. Rowney (2005), 'Sustainable development: lost meaning and opportunity?', Journal of Business Ethics 60(1): 17-27.

Foster, V., J. Tre and Q. Wodon (2000), 'Energy prices, energy efficiency and fuel poverty', [Available at] http://info.worldbank.org/etools/docs/voddocs/240/ 502/Gua_price.pdf.

Gujarati, D.N. and D.C. Porter (2009), Basic Econometrics, 5th edn, New York: McGraw-Hill. 
IEA and OECD (2004), World Energy Outlook 2004, Paris: International Energy Agency and Organisation for Economic Cooperation and Development.

Iwayemi, A. (2010), ' Energy poverty in Africa: introduction and overview', Paper presented at the International Workshop on Energy Poverty in Africa, 8-10 June 2008, OPEC Fund for International Development (OFID), Vienna.

Martins, J. (2005), 'The impact of the use of energy sources on the quality of life of poor communities', Social Indicators Research 72(3): 373-402.

NBS (2005), Poverty Profile for Nigeria, Abuja: National Bureau of Statistics.

NBS (2010), Nigeria Living Standard Survey (NLSS) Data Set, Abuja: National Bureau of Statistics.

Nussbaumer, P., M. Bazilian, V. Modi, and K.K. Yumkella (2011), 'Measuring energy poverty: focusing on what matters', Oxford Poverty \& Human Development Initiative (OPHI) Working Paper Series No. 42, University of Oxford, Oxford.

Nussbaumer, P., M. Bazilian, and V. Modi (2012), 'Measuring energy poverty: focusing on what matters', Renewable and Sustainable Energy Reviews 16(1): 231-243.

OECD/IEA (2010), 'Energy poverty: how to make modern energy access universal', [Available at] http://www.se4all.org/wp-content/uploads/2013/09/Special_ Excerpt_of_WEO_2010.pdf.

Ogwumike, F.O. and U.M. Ozughalu (2012), ‘Energy consumption, poverty and environmental linkages in Nigeria: a case of traditional and modern fuels for cooking', in A. Adenikinju, A. Iwayemi and W. Iledare (eds), Green Energy and Energy Security: Options for Africa, Ibadan: Atlantis Books, pp. 235-254.

Onyeji, I., M. Bazilian, and P. Nussbaumer (2012), 'Contextualizing electricity access in sub-Saharan Africa', Energy for Sustainable Development 16(4): 520-527.

Ouedraogo, B. (2006), 'Household energy preferences for cooking in Urban Ouagadougou, Burkina Faso', Energy Policy 34(18): 3787-3795.

Ozughalu, U.M. (2010), 'Basic food consumption, poverty and vulnerability in Nigeria', PhD thesis, University of Ibadan, Nigeria.

Pachauri, S. and D. Spreng (2004), 'Energy use and energy access in relation to poverty', Economic and Political Weekly 39(3): 271-278.

Pachauri, S. and D. Spreng (2011), 'Measuring and monitoring energy poverty', Energy Policy 39(12): 7497-7504.

Robic, S., M. Olshanskaya, R. Vrbensky, and Z. Morvag (2012), 'Understanding energy poverty - case study: Tajikistan', [Available at] http:/ / www.worldenergy. org/documents/congresspapers/339.pdf.

Sambo, A.S. (2009), 'Strategic development in renewable energy in Nigeria', [Available at] https://www.iaee.org/en/publications/newsletterdl.aspx?id=75.

Sher, F., A. Abbas, and R.U. Awan (2014), 'An investigation of multidimensional energy poverty in Pakistan: a province level analysis', International Journal of Energy Economics and Policy 4(1): 65-75.

Todaro, M.P. and S.C. Smith (2011), Economic Development, 11th edn, Harlow: Addison-Wesley.

UN (1987), 'Our common future', Report of the World Commission on Environment and Development, New York: United Nations, [Available at] http://www.undocuments.net/our-common-future.pdf.

UN (2005), The Energy Challenge for Achieving the Millennium Development Goals, New York: United Nations, [Available at] http://mirror.unhabitat.org/downloads/ docs $/ 923$ 32269_The $\% 20$ Energy $\% 20$ challenge $\% 20$ for $\% 20$ achieving $\% 20$ the $\%$ 20millenium\%20development\%20goals.pdf.

UNDP and WHO (2009), The Energy Access Situation in Developing Countries: A Review Focusing on the Least Developed Countries and Sub-Saharan Africa, New York: United Nations Development Programme and World Health Organisation.

World Bank (2012), Household Energy Access for Cooking and Heating: Lessons Learned and the Way Forward, Washington, DC: World Bank. 